\title{
National, regional, and worldwide estimates of preterm birth rates in the year 2010 with time trends since 1990 for selected countries: a systematic analysis and implications
}

\author{
Hannah Blencowe, Simon Cousens, Mikkel Z Oestergaard, Doris Chou, Ann-Beth Moller, Rajesh Narwal, Alma Adler, Claudia Vera Garcia, \\ Sarah Rohde, Lale Say, Joy E Lawn
}

\section{Summary}

Lancet 2012; 379: 2162-72

See Comment page 2128

London School of Hygiene and Tropical Medicine, London, UK (H Blencowe MRCPCH,

Prof S Cousens DipMathStat,

R Narwal MD, A Adler PhD,

(Vera Garcia MPH); World

Health Organization, Geneva,

Switzerland

(M Z Oestergaard PhD,

D Chou MD, A-B Moller Msc, L Say MD); University of Cape

Town, Cape Town, South Africa

(S Rohde MPH); and Saving

Newborn Lives, Save the

Children, Cape Town, South Africa (J E Lawn MRCP Paeds)

Correspondence to:

Dr Joy Lawn

joylawn@yahoo.co.uk

Background Preterm birth is the second largest direct cause of child deaths in children younger than 5 years. Yet, data regarding preterm birth (<37 completed weeks of gestation) are not routinely collected by UN agencies, and no systematic country estimates nor time trend analyses have been done. We report worldwide, regional, and national estimates of preterm birth rates for 184 countries in 2010 with time trends for selected countries, and provide a quantitative assessment of the uncertainty surrounding these estimates.

Methods We assessed various data sources according to prespecified inclusion criteria. National Registries (563 datapoints, 51 countries), Reproductive Health Surveys (13 datapoints, eight countries), and studies identified through systematic searches and unpublished data (162 datapoints, 40 countries) were included. 55 countries submitted additional data during WHO's country consultation process. For 13 countries with adequate quality and quantity of data, we estimated preterm birth rates using country-level loess regression for 2010. For 171 countries, two regional multilevel statistical models were developed to estimate preterm birth rates for 2010. We estimated time trends from 1990 to 2010 for 65 countries with reliable time trend data and more than 10000 livebirths per year. We calculated uncertainty ranges for all countries.

Findings In 2010, an estimated $14 \cdot 9$ million babies (uncertainty range $12 \cdot 3-18 \cdot 1$ million) were born preterm, 11.1\% of all livebirths worldwide, ranging from about $5 \%$ in several European countries to $18 \%$ in some African countries. More than $60 \%$ of preterm babies were born in south Asia and sub-Saharan Africa, where $52 \%$ of the global livebirths occur. Preterm birth also affects rich countries, for example, USA has high rates and is one of the ten countries with the highest numbers of preterm births. Of the 65 countries with estimated time trends, only three (Croatia, Ecuador, and Estonia), had reduced preterm birth rates 1990-2010.

Interpretation The burden of preterm birth is substantial and is increasing in those regions with reliable data. Improved recording of all pregnancy outcomes and standard application of preterm definitions is important. We recommend the addition of a data-quality indicator of the per cent of all live preterm births that are under 28 weeks' gestation. Distinguishing preterm births that are spontaneous from those that are provider-initiated is important to monitor trends associated with increased caesarean sections. Rapid scale up of basic interventions could accelerate progress towards Millennium Development Goal 4 for child survival and beyond.

Funding Bill \& Melinda Gates Foundation through grants to Child Health Epidemiology Reference Group (CHERG) and Save the Children's Saving Newborn Lives programme; March of Dimes; the Partnership for Maternal Newborn and Childe Health; and WHO, Department of Reproductive Health and Research.

\section{Introduction}

Preterm birth complications are estimated to be responsible for $35 \%$ of the world's $3 \cdot 1$ million annual neonatal deaths, and are now the second most common cause of death after pneumonia in children under 5 years old. ${ }^{1}$ Preterm birth also increases the risk of death due to other causes, especially from neonatal infections, ${ }^{2,3}$ and in almost all high-income and middle-income countries, preterm birth is the leading cause of child deaths. ${ }^{1}$ Additional to its contribution to mortality, preterm birth has lifelong effects on neurodevelopmental functioning such as increased risk of cerebral palsy, impaired learning and visual disorders, and an increased risk of chronic disease in adulthood. ${ }^{4}$ The economic cost of preterm birth is high in terms of neonatal intensive care and ongoing health-care and educational needs. The social cost is also high, with many families experiencing the sudden loss of a preterm baby or a stressful hospital stay, sometimes for months.

The WHO defines preterm birth as any birth before 37 completed weeks of gestation, or fewer than 259 days since the first day of the women's last menstrual period $(\mathrm{LMP})^{6}$ and this can be further subdivided on the basis of gestational age: extremely preterm $(<28$ weeks $)$, very preterm $(28-<32$ weeks), and moderate or late preterm $(32-<37$ completed weeks of gestation; figure 1). These subdivisions are important since decreasing gestational age is associated with increasing mortality, disability, intensity of neonatal care required, and hence increasing costs. 
Preterm birth is a syndrome with a variety of causes which can be broadly classified into two groups: (1) spontaneous preterm birth and (2) provider-initiated preterm birth (defined as induction of labour or elective caesarean section before 37 completed weeks of gestation for maternal or fetal indications or other non-medical reasons, and sometimes previously called "iatrogenic").? Globally, the highest burden countries have very low levels of provider-initiated preterm births, with most African countries having caesarean sections rates lower than $5 \% .^{8}$ However, many high-income and middleincome countries have increasingly high numbers of provider-initiated preterm births and a recent assessment of 872 provider-initiated preterm births at 34-36 weeks' gestation in the USA suggested that more than half were done in the absence of a well defined medical indication. ${ }^{9}$

Spontaneous preterm birth is a multifactorial process, resulting from the interplay of factors causing the uterus to change from quiescence to active contractions and to birth before 37 completed weeks of gestation. The precursors vary by gestational age, ${ }^{10}$ with the precise cause of spontaneous preterm labour being unidentified in up to half of all cases. ${ }^{11}$ Individual or family history of preterm birth is a strong risk factor. ${ }^{12}$ Many other maternal factors have been associated with an increased risk of spontaneous preterm birth, including young or advanced maternal age, short interpregnancy intervals, low maternal body-mass index (BMI), multiple pregnancy, pre-existing non-communicable disease, hypertensive disease of pregnancy, and infections. ${ }^{13,14}$

The number of liveborn preterm babies, whether singleton or multiple births, is the numerator for preterm birth rates. Liveborn preterm babies drive the need for neonatal care, and in high-income countries half of babies under 25 weeks now survive, but with increasing evidence of major disability. ${ }^{15}$ By contrast, in low-income and many middle-income settings, moderate and late preterm babies do not have even basic care and account for most preterm babies dying. However, from a public health perspective for policy and planning, and from a family loss perspective, both liveborn and stillborn babies born before term are important (figure 1).

The International Classification of Diseases: tenth revision (ICD-10) recommends recording all newborns with any signs of life at birth as livebirths. ${ }^{16}$ However, for extremely preterm babies, practice is variable and is closely linked to perceptions of viability and stillbirth registration thresholds. Classifications vary between countries and over time, complicating the comparison of reported rates and interpretation of time trends (figure 1). ${ }^{17,18}$ Furthermore, some reports exclude babies with congenital abnormalities, and others include only singleton births. Additionally, methods for assessing gestational age have improved over time, at least in high-income countries, and variations in methods for measurement of gestational age further complicate the interpretation of preterm birth rates both within and between countries.

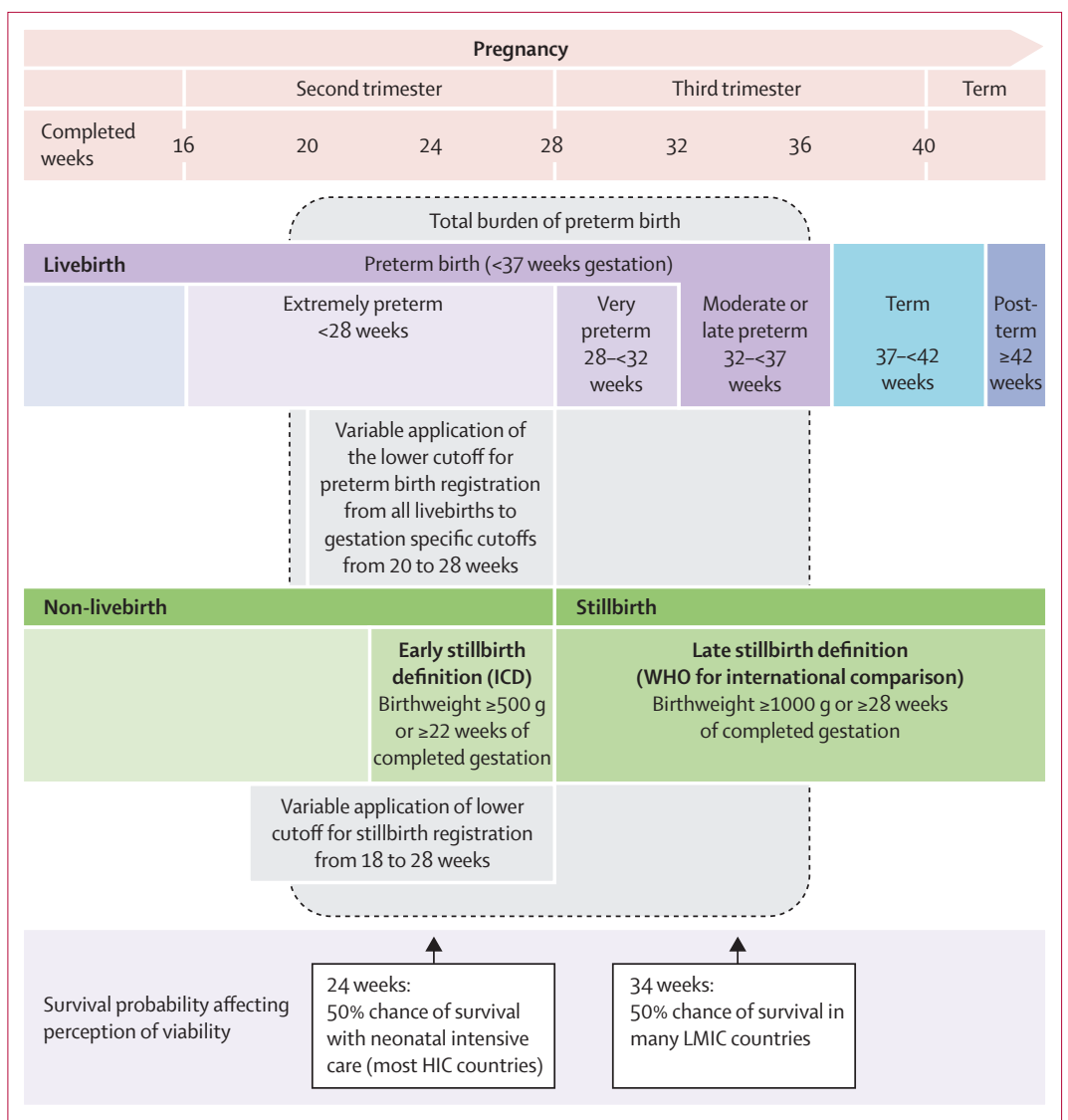

Figure 1: Overview of definitions and variable cutoffs applied for pregnancy outcomes related to preterm birth and stillbirths

Figure adapted from Lawn and colleagues. ${ }^{17} \mathrm{HIC}=$ high-income countries. $\mathrm{LMIC}=$ low-income and middle-income countries. *Very preterm group in this analysis includes babies $28-<32$ weeks and extremely preterm births are defined as $<28$ weeks.

These differences and the absence of routinely collected data on preterm birth rates in many countries have limited the understanding of the size of the burden of preterm birth globally. A previous exercise estimated that $9.6 \%$ of livebirths worldwide in 2005 were preterm (12.9 million preterm births). ${ }^{19}$ No national systematic estimates of preterm birth rates have been published, ${ }^{20}$ and no multicountry time trend analysis is available.

In this study, we report worldwide, regional, and national estimates of preterm birth rates for 184 countries in 2010, and provide a quantitative assessment of the uncertainty surrounding these estimates. We have based the regional estimates on the Millennium Development Goal (MDG) regions (appendix p 1). ${ }^{21}$ We also present trend estimates for the period 1990-2010, where sufficient data exist. In the interests of public health planning, we also estimate preterm birth by three subgroups-namely, extremely preterm, very preterm, and moderate or late preterm (figure 1).

For the purpose of these estimates, the definition of the preterm birth rate used is "all livebirths before 37 completed weeks, whether singleton, twin, or higher order multiples, divided by all livebirths in the population". 


\section{Methods}

Data inputs

We assessed preterm birth data for inclusion from four sources: national registries or statistical offices, Reproductive Health Surveys, ${ }^{22}$ unpublished data from principal investigators collaborating with the Child Health

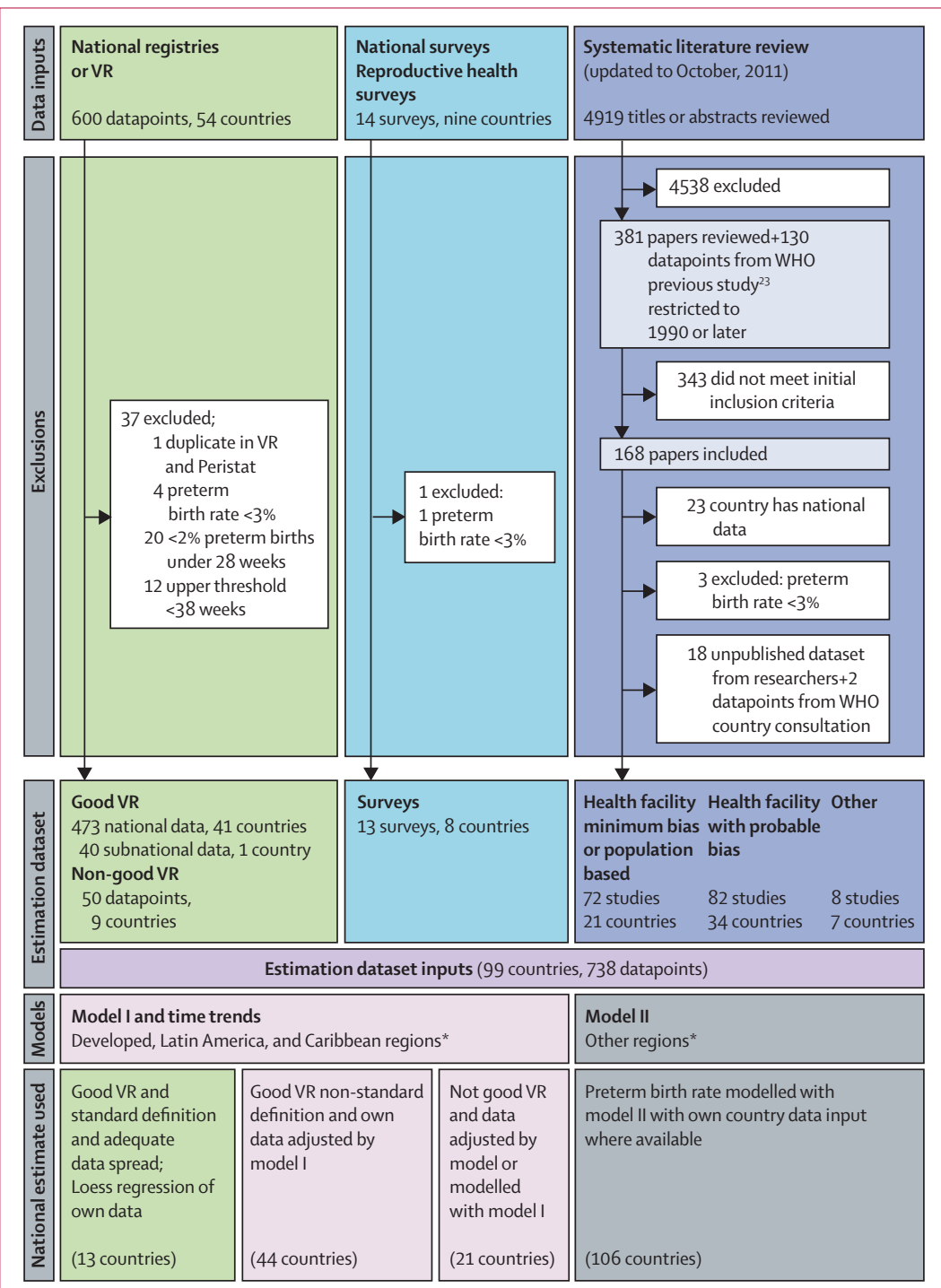

Figure 2: Preterm birth rate data search strategy, selection progress showing the methods, and models used for estimation

VR=vital registration. Good VR= national VR with high-quality reporting for maternal deaths. ${ }^{25}$ * Millennium Development Goal regions.

\begin{tabular}{|c|c|c|}
\hline & Gestational age & Proportion of all $<37$ weeks $(\%, 95 \% \mathrm{Cl})$ \\
\hline Extremely preterm & $<28$ weeks & $5 \cdot 2 \%(5 \cdot 1-5 \cdot 3)$ \\
\hline Very preterm & $28-<32$ weeks & $10 \cdot 4 \%(10 \cdot 3-10 \cdot 5)$ \\
\hline Moderate or late preterm & $32-<37$ weeks & $84 \cdot 3 \%(84 \cdot 1-84 \cdot 5)$ \\
\hline
\end{tabular}

Epidemiology Reference Group, and published papers identified through a systematic review (figure 2).

We systematically searched all the National Statistical Offices websites ${ }^{24}$ and Ministry of Health websites. For countries without National Statistical Office or Ministry of Health data, we searched for data from nationally representative household Health Surveys. ${ }^{22}$ For countries with less robust national health registration systems (those classified as not having national vital registration with high-quality reporting for maternal deaths), ${ }^{25}$ we did a systematic review of all the main online literature databases. Search terms used included multiple variants of terms covering the following areas "preterm or premature" and "birth or labour" or "newborn or infant" and we used Medical Subject Headings terms when available (appendix pp 3-4 lists the databases that were searched and the full set of search terms used). Unpublished data from principle investigators collaborating with the Child Health Epidemiology Reference Group, and data from the WHO Global Health Survey were requested.

\section{Data inclusion and exclusion criteria}

We assessed all reports that included more than 50 births with a midpoint of data collection of 1990 or later and in which a preterm birth rate was given or could be calculated. Although we aimed to estimate the preterm rate using a standard definition, we included data using other definitions and sought to account for the different definitions in the modelling. Data from specialised services reports were excluded as non-generalisable for example diabetes, hypertension, intrauterine growth restriction, or specific subpopulations or ethnic groups. Data from health facilities with potential for selection bias were included and identified using a dummy variable similar to a previous estimation exercise for stillbirth rates. ${ }^{26}$

Data were excluded if obtained over a period of less than 12 months unless the source stated no seasonality, or data from the same source for another year showed no seasonality. We excluded datapoints likely to reflect poor case ascertainment on the basis of two conservative criteria: (1) less than $3 \%$ of all births reported to be preterm, since the lowest reliable national reported rates identified in our database were about $5 \%$ and less than $3 \%$ was deemed biologically implausible on the basis of this distribution; (2) less than $2 \%$ of all preterm births at less than 28 weeks' gestation, as based on our meta-analysis of the distribution of gestational age subgroups, which showed that the proportion of births at less than 28 weeks' gestation was very consistent at about $5 \%$ (table 1).

A country consultation process was carried out by WHO involving circulation to Member States of WHO of the national input data, together with estimation methods and the preliminary preterm birth estimates. Countries were asked to review and provide feedback and any relevant additional data. 55 countries provided 
additional data, and if criteria were met, these were included in the final dataset and the estimates remodelled based on this dataset (figure 2).

\section{Final dataset used as input for statistical models}

The final dataset used included 738 datapoints (figure 2). Most datapoints (539 of $738,73 \%$ ) were from National Statistical Offices, Ministry of Health databases, or nationally representative surveys; ${ }^{22} 103$ (14\%) were derived from subnational, population-based sources or hospitalbased studies in settings with institutional birth rates higher than $90 \%$ (assumed to provide unbiased estimates of the population preterm birth rate), and $11 \%$ were from hospital-based studies in settings with institutional birth rates lower than $90 \%$ where preterm birth rates might not be representative of the population rates. 547 (74\%) datapoints were from countries in MDG regions Developed, Latin America, and the Caribbean (median year 2002). 191 datapoints (26\%; median year 2002), were from countries in other regions; these regions had few high-quality datapoints. The preterm birth rate based on the standard definition was available for 612 datapoints, with most (101) of the remaining datapoints including only singleton livebirths. For 85 countries, no data were available (appendix pp 5-54).

\section{Statistical models}

For 13 countries classified as having good vital registration for maternal deaths, ${ }^{25}$ using the standard definition for preterm birth, and with data for more than $50 \%$ of the years 1990-2010 including at least one year before 1995 and one year after 2005, we used country-level loess regression to estimate preterm birth rates for all years (appendix pp 55-56).

For all other countries, preterm birth rates were modelled using preterm birth data from the country itself, when available, along with other countries' preterm birth data. Since regional variation existed in the quality of data available and the underlying causes and predictors of preterm birth between high-income settings and the rest of the world, two regional models were developed. Model I included 65 countries in the MDG regions "Developed region", and "Latin America" and "the Caribbean", including 547 data inputs from 52 countries. Model II provided estimates of preterm birth rates in all other world regions (for 106 countries, including 191 data inputs from 47 countries). Table 2 shows covariates investigated as potential predictors.

Where data for continuous predictors were not available for all years 1990-2010 for all the countries, the missing years were interpolated using loess regression or linear interpolation (appendix pp 57-59 for details of sources, methodology and univariate analysis). We examined both restricted cubic splines and linear trends when assessing the relationship between the outcome and these potential continuous predictors. The final modelling approach was determined by the best fit to the data.
The models were fitted with a forward step-wise approach, retaining variables if there was evidence of predictive value existed after taking account of the other variables in the model $(\mathrm{p}<0 \cdot 10)$ or, for variables relating to the methodology used, if the coefficients were of the expected sign and of plausible magnitude. Both models included a country-level random effect. For countries contributing data to the input dataset, the best linear unbiased prediction of the country-specific random effect was obtained and used in predicting that country's preterm birth rate. If no national data were available the random effect was assumed to be zero. Variables retained in Model I included: linear log (low birthweight rate) $(\mathrm{p}<0.0001)$, mean adult female BMI $(\mathrm{p}=0.09)$, year $(p<0 \cdot 0001)$, data source $(p<0 \cdot 0001)$, method of gestational age assessment $(\mathrm{p}<0 \cdot 0001)$, and denominator (singleton or all births) $(\mathrm{p}=0 \cdot 004$; table 2 , appendix $\mathrm{p} 60$ for full model equation). The preterm birth rate increased with increasing low birthweight rate and mean adult female BMI (appendix p 61). Regression diagnostic plots

\begin{tabular}{|c|c|c|c|c|}
\hline & $\begin{array}{l}\text { Retained in } \\
\text { Model I }\end{array}$ & Risk ratio $(95 \% \mathrm{Cl})$ & $\begin{array}{l}\text { Retained in } \\
\text { Model II }\end{array}$ & Risk ratio $(95 \% \mathrm{Cl})$ \\
\hline Neonatal mortality rate & No & .. & No & .. \\
\hline Low birthweight rate & Yes & $1 \cdot 40(1 \cdot 26-1 \cdot 56)$ & Yes & $1 \cdot 34(1 \cdot 17-1 \cdot 53)$ \\
\hline Caesarean section rate & No &.. & No &.. \\
\hline Adolescent pregnancy rate & No & .. & No & .. \\
\hline HIV prevalence & No &.. & No &.. \\
\hline Malaria endemicity & No &.. & Yes & $1.17(0.99-1.37)$ \\
\hline Mean adult female BMI & Yes & $1.03(1.00-1.06)$ & No & .. \\
\hline Gross National Income & No &.. & No &.. \\
\hline General fertility rate & No &.. & No &.. \\
\hline Female literacy rate & No &.. & Yes & $1.01(1.00-1.01)$ \\
\hline MDG region & No & .. & No & .. \\
\hline Preterm definition & No &.. & No & .. \\
\hline Upper and lower cutoff & .. & .. & No & .. \\
\hline $\begin{array}{l}\text { Method of gestational age } \\
\text { assessment }\end{array}$ & Yes & .. & Yes & .. \\
\hline $\begin{array}{l}\text { Ultrasound, best obstetric } \\
\text { estimate }\end{array}$ & .. & 1.00 &.. & 1.00 \\
\hline Last menstrual period &.. & $1 \cdot 15(1.04-1 \cdot 26)$ & .. & $1.12(0.93-1.36)$ \\
\hline Other & .. & $0.75(0.66-0.84)$ & .. & $0 \cdot 87(0 \cdot 75-1 \cdot 01)$ \\
\hline Singleton/all births & Yes & .. & Yes & .. \\
\hline Singleton &.. & 1.00 &.. & 1.00 \\
\hline All births & .. & $1 \cdot 12(1.05-1 \cdot 20)$ & .. & $1.06(0.93-1.21)$ \\
\hline Not known &.. & $1.15(0.94-1.42)$ &.. & $1 \cdot 31(0 \cdot 82-2 \cdot 11)$ \\
\hline Livebirths/total births & No & .. & No & .. \\
\hline Year of study & Yes & $1.01(1.00-1.01)$ & No & .. \\
\hline Type of data source & Yes & .. & Yes & .. \\
\hline National & .. & 1.00 & .. & 1.00 \\
\hline Subnational & .. & $1.36(1.06-1.75)$ & .. & $1.47(1.10-1.97)$ \\
\hline Facility-possible bias/other &.$\cdot$ & $1 \cdot 40(1 \cdot 26-1 \cdot 56)$ &.. & $1.24(0.96-1.61)$ \\
\hline \multicolumn{5}{|c|}{ BMI=body-mass index. MDG=Millennium Development Goal. } \\
\hline
\end{tabular}


suggest that the model fits the data well (overall $R^{2}=0 \cdot 4$; appendix p 62).

Variables retained in Model II included: linear log (low birthweight rate) $(\mathrm{p}<0 \cdot 0001)$, malaria endemicity $(\mathrm{p}=0.06)$, female literacy rate $(\mathrm{p}=0.04)$, data source $(p=0 \cdot 02)$, method of gestational age assessment $(p=0 \cdot 01)$, and denominator (singleton or all births; $\mathrm{p}=0.40$; table 2 , see appendix p 60 for full model equation). Preterm birth rates increased with increasing low birthweight rate, malaria, and female literacy (table 2; appendix $\mathrm{p}$ 61). Regression diagnostic plots show the fit of the model to the data (overall $\mathrm{R}^{2}=0 \cdot 29$; appendix $\mathrm{p}$ 63).

The numbers of preterm births by country were derived by applying our preterm birth rate estimations to the UN

\begin{tabular}{|lrlc|}
\hline & $\begin{array}{l}\text { Number of } \\
\text { livebirths }\end{array}$ & $\begin{array}{l}\text { Estimated mean } \\
\text { preterm birth rate }(\%) \\
\text { (uncertainty range* }\end{array}$ & $\begin{array}{l}\text { Number of preterm births } \\
\text { (uncertainty range*) }\end{array}$ \\
\hline Developed regions & 14300000 & $8 \cdot 6 \%(8 \cdot 3-9 \cdot 4)$ & $1233200(1188500-1345100)$ \\
\hline Eastern Asia & 17400000 & $7 \cdot 2 \%(5 \cdot 4-9 \cdot 0)$ & $1262200(943100-1564100)$ \\
\hline Latin America & 10200000 & $8 \cdot 4 \%(6 \cdot 8-11 \cdot 4)$ & $852800(695500-1164000)$ \\
\hline Northern Africa & 3543100 & $7 \cdot 3 \%(4 \cdot 8-10 \cdot 9)$ & $259200(168700-387900)$ \\
\hline Oceania & 263200 & $7 \cdot 4 \%(4 \cdot 5-15 \cdot 6)$ & $19500(11800-41000)$ \\
\hline Southeastern Asia & 11000000 & $13 \cdot 6 \%(9 \cdot 3-18 \cdot 6)$ & $1497500(1019400-2044700)$ \\
\hline Southern Asia & 38700000 & $13 \cdot 3 \%(10 \cdot 1-16 \cdot 8)$ & $5159300(3900100-6504200)$ \\
\hline Sub-Saharan Africa & 32100000 & $12 \cdot 3 \%(9 \cdot 5-15 \cdot 8)$ & $3936800(3039500-5068000)$ \\
\hline Western Asia & 4855300 & $10 \cdot 1 \%(6 \cdot 9-14 \cdot 3)$ & $488200(334000-693700)$ \\
\hline Caribbean & 682800 & $11 \cdot 2 \%(7 \cdot 8-20 \cdot 8)$ & $76500(53300-142000)$ \\
\hline Caucasus and Central Asia & 1643000 & $9 \cdot 2 \%(6 \cdot 0-13 \cdot 0)$ & $151300(99100-212800)$ \\
\hline Total worldwide & 135000000 & $11 \cdot 1 \%(9 \cdot 1-13 \cdot 4)$ & $14936700(12268200-18089700)$ \\
\hline *Uncertainty ranges derived using a bootstrap approach see appendix 64. & \\
\hline Table 3: Estimated preterm birth rates and total number of preterm births for 2010, by Millennium \\
Development Goal region
\end{tabular}

estimate of livebirths for that country and the relevant year, taking account of demographic trends. ${ }^{27}$

\section{Statistical analysis}

To estimate the distribution of preterm births by gestational age subgroup, we did a meta-analysis of all 345 datapoints in our input database which presented data by our agreed gestational age subgroups $(\mathrm{N}=131296765$; table 1). The median year of these data was 2004 (range 1990-2010). A random effects model was used as some evidence of heterogeneity, assessed using $I^{2}$ and the $\chi^{2}$ test, was present $(p<0 \cdot 10)$. The proportions were remarkably similar across these datasets suggesting a biological basis for the distribution. Given this consistency, we applied these proportions to our estimates of preterm births for all countries for 2010. However, only 13\% (44 datapoints) were from outside the Developed region, with only seven datapoints from southern Asia, or sub-Saharan Africa. There was some evidence of a difference in the distributions of the subgroups for all other regions, compared with Developed region, reported on average slightly lower proportions of preterm births at less than 28 weeks $(4.8 \%$ vs $5.3 \%$; $\mathrm{p}=0.02)$; similar proportions of preterm births for 28 to less than 32 weeks (10.2\% vs $10.6 \% ; \mathrm{p}=0 \cdot 13)$; and higher proportions for births at 32 weeks to less than 37 weeks $(85 \cdot 1 \%$ vs $84.1 \%$; $\mathrm{p}=0.03)$ ). These differences are likely to represent differences in case ascertainment in the group of less than 28 weeks' gestation between regions. We did not estimate trends for the gestational age subgroups.

We estimated the uncertainty around the gestational age subgroups as $95 \%$ CIs using a probabilistic method (table 1) since there were large and consistent datasets. However a probabilistic approach would be misleading for country estimates with limited or no input data since

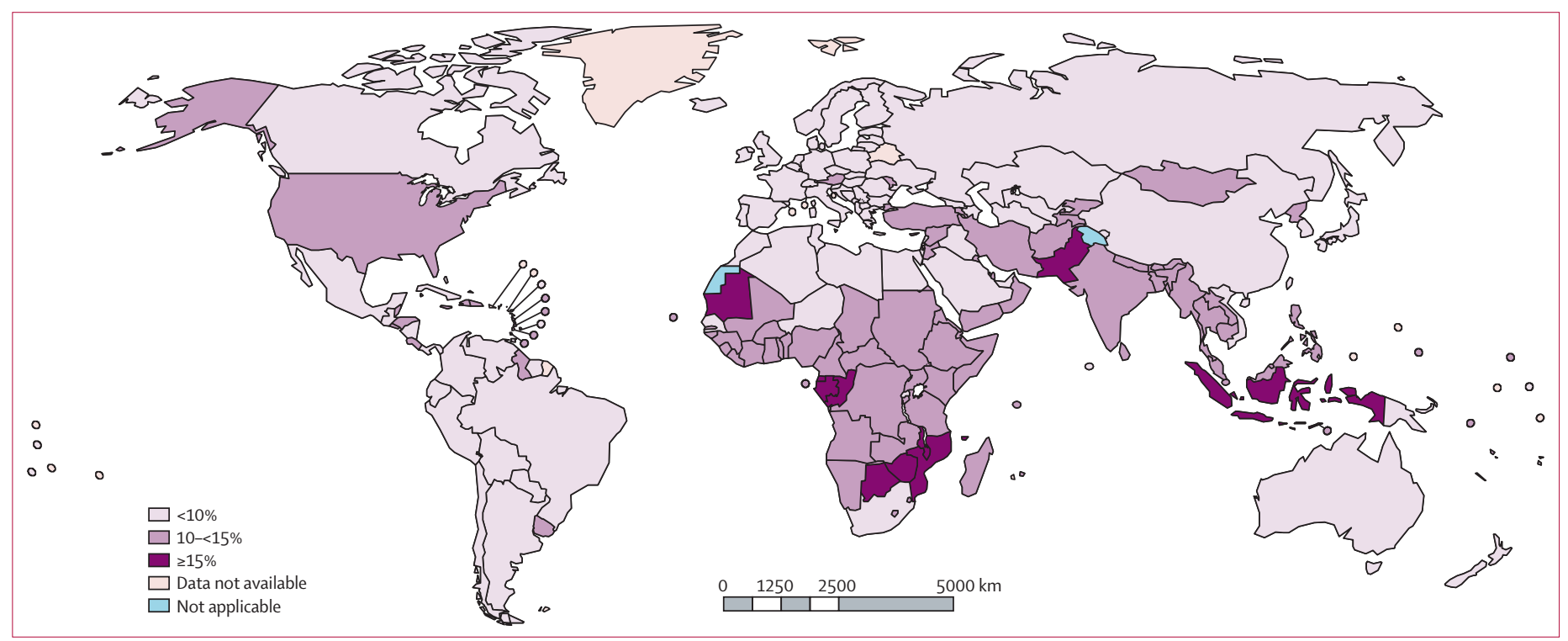

Figure 3: Estimated preterm birth rates by country for the year 2010 
fewer data might result in the appearance of narrower uncertainty, or no data is taken to be no uncertainty when such estimates would be expected to have the widest uncertainty. We used a statistical approach based on the model to estimate uncertainty ranges for national preterm birth rates for Model I, Model II, and loess countries separately using a bootstrap approach (appendix p 64).

We estimated trends for the 65 countries in Developed, Latin America, and the Caribbean regions with over 10000 livebirths in 2010, using loess regression (12 countries, excluding Luxembourg $<10000$ births) or Model I estimates (53 countries) as described above. We did not estimate trends in other regions because of the absence of consistent data over the 21 year period.

\section{Funding}

The funding source had no role in study design, data collection, data analysis, data interpretation, or writing of the report. HB, DC, ABM, LS, SC, and JEL had full access to all the data. $\mathrm{HB}, \mathrm{SC}$, and JEL had final responsibility to submit for publication.

\section{Results}

Based on 184 countries, the global average preterm birth rate in 2010 was $11 \cdot 1 \%$ (uncertainty range $9 \cdot 1-13 \cdot 4 \%$ ), giving a worldwide total of $14 \cdot 9$ million $(12 \cdot 3-18 \cdot 1$ million; table 3$)$. Preterm birth rates varied widely between countries (figure 3; appendix pp 65-72 and country plots for individual country data). At a national level, the estimated preterm birth rate ranged from about $5 \%$ in several northern European countries to $18 \%$ in Malawi. In 88 countries, this rate was lower than $10 \%$. Of the 11 countries with estimated rates of $15 \%$ or more in 2010 , all but two were in sub-Saharan Africa (figure 3). Rates are highest for low-income countries $(11 \cdot 8 \%)$, followed by lower middleincome countries $(11.3 \%)$, and lowest for upper middlecountries $(9.4 \%)$ and high-income countries $(9.3 \%)$. High preterm birth rates were also noted in many highincome countries (eg, USA at $12.0 \%$ and Austria at $10 \cdot 9 \%)$, making a major contribution to child mortality and morbidity.

The regions with the highest preterm birth rates in 2010 were Southeastern Asia, South Asia, and subSaharan Africa (figure 4). More than $60 \%$ of all preterm births are estimated to have occurred in sub-Saharan Africa and South Asia where 9.1 million livebirths (12.8\% of livebirths) were estimated to be preterm in 2010. Table 4 lists the ten countries with the highest numbers of estimated preterm births, accounting for $60 \%$ of all preterm births. USA alone accounts for $42 \%$ of all preterm births in the Developed region ( $>0.5$ million), but only $30 \%$ of the region's livebirths.

No evidence of a systematic difference existed between the estimated preterm birth rates for 2010 and the nationally reported rate in the 26 countries with available data for 2009 or 2010 using the standard definition and of acceptable quality (paired $t$ test $\mathrm{p}=0 \cdot 84$ ). ${ }^{24}$ The median difference between estimated and reported rates was $-0 \cdot 3 \%$ (IQR $-1 \cdot 3$ to $2 \cdot 3 \%$; appendix pp $73-74$ ).

Applying the estimated distribution of gestational age subgroups to every country (table 1), in 2010, an estimated 0.78 million (uncertainty range $0.76-0.87$ million) preterm babies were extremely preterm, 1.6 million (1.5-1.7 million) were very preterm, and most (12.6 million, $12 \cdot 3-14 \cdot 1$ million; $84 \%$ ) were moderate and late preterm (figure 4, appendix p 75).

Time trends for preterm birth rates were estimated for 65 countries in Developed and Latin America and the Caribbean regions with more than 10000 births in the year 2010. The mean estimated rate in these countries for 1990 was $7 \cdot 5 \%$ (total preterm births in these countries $2 \cdot 0$ million, uncertainty range $1 \cdot 8-2 \cdot 5$ million preterm births) compared with $8.6 \%$ (total preterm births $2 \cdot 2$ million, $2 \cdot 0-2 \cdot 6$ million preterm births) in 2010 (table 5). Only three countries, Croatia, Ecuador, and

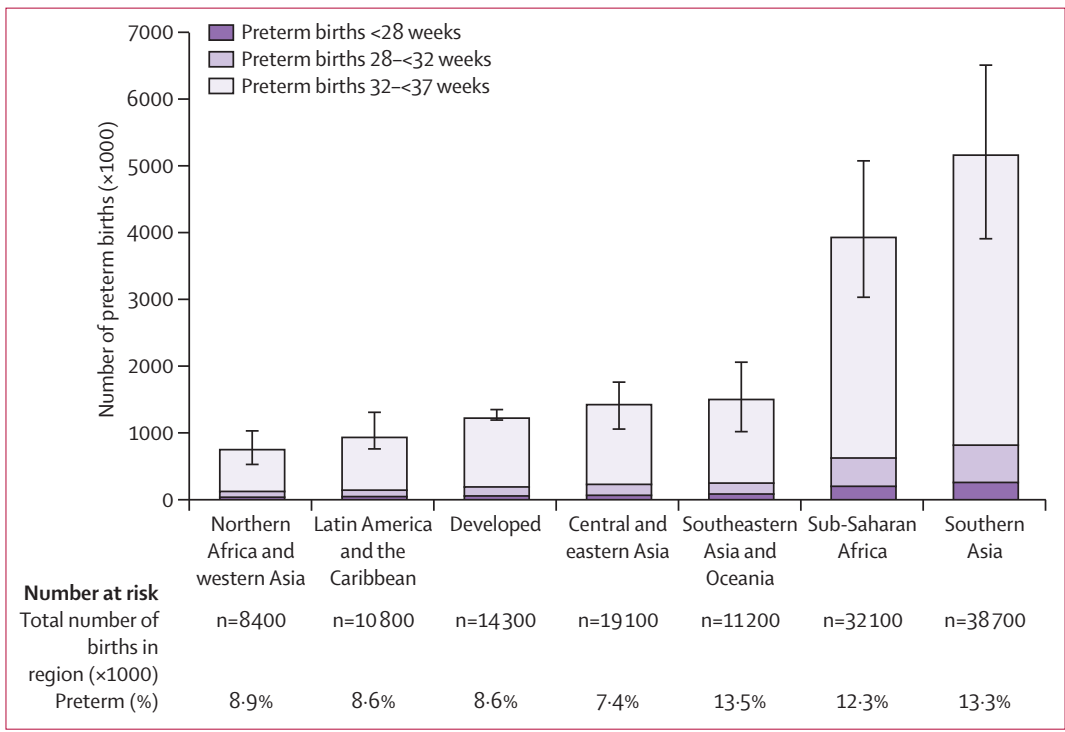

Figure 4: Estimated preterm births by region and by gestational age grouping for the year 2010

\begin{tabular}{|lcclc|}
\hline & $\begin{array}{l}\text { Rank for } \\
\text { number of } \\
\text { preterm births }\end{array}$ & $\begin{array}{l}\text { Number of preterm } \\
\text { births (\% of global total) }\end{array}$ & $\begin{array}{l}\text { Preterm birth } \\
\text { rate (\% of } \\
\text { livebirths) }\end{array}$ & $\begin{array}{l}\text { Number of livebirths } \\
\text { (\% of global total) }\end{array}$ \\
\hline India & 1 & $3519118(23 \cdot 6 \%)$ & $13 \cdot 0 \%$ & $27200000(20 \cdot 1 \%)$ \\
\hline China & 2 & $1172259(7 \cdot 8 \%)$ & $7 \cdot 1 \%$ & $16600000(12 \cdot 3 \%)$ \\
Nigeria & 3 & $773597(5 \cdot 2 \%)$ & $12 \cdot 2 \%$ & $6332251(4 \cdot 7 \%)$ \\
\hline Pakistan & 4 & $748142(5 \cdot 0 \%)$ & $15 \cdot 8 \%$ & $4741460(3 \cdot 5 \%)$ \\
Indonesia & 5 & $675744(4 \cdot 5 \%)$ & $15 \cdot 5 \%$ & $4371818(3 \cdot 2 \%)$ \\
\hline USA & 6 & $517443(3 \cdot 5 \%)$ & $12 \cdot 0 \%$ & $4300620(3 \cdot 2 \%)$ \\
\hline Bangladesh & 7 & $424144(2 \cdot 8 \%)$ & $14 \cdot 0 \%$ & $3037652(2 \cdot 3 \%)$ \\
\hline Philippines & 8 & $348871(2 \cdot 3 \%)$ & $14 \cdot 9 \%$ & $2344154(1 \cdot 7 \%)$ \\
\hline $\begin{array}{l}\text { Democratic Republic } \\
\text { of Congo }\end{array}$ & 9 & $341421(2 \cdot 3 \%)$ & $11 \cdot 9 \%$ & $2872606(2 \cdot 1 \%)$ \\
\hline Brazil & 10 & $279256(1 \cdot 9 \%)$ & $9 \cdot 2 \%$ & $3022823(2 \cdot 2 \%)$ \\
\hline Total &.. & 8.8 million (59\%) &.. & $74 \cdot 8$ million $(55 \%)$ \\
\hline Table 4: The ten countries with the highest numbers of preterm births in 2010 & \\
\hline
\end{tabular}




\begin{tabular}{|c|c|c|c|c|c|c|c|c|}
\hline & \multicolumn{3}{|l|}{1990} & \multicolumn{3}{|l|}{2010} & \multicolumn{2}{|l|}{$1990-2010$} \\
\hline & $\begin{array}{l}\text { Number of } \\
\text { livebirths }\end{array}$ & $\begin{array}{l}\text { Preterm birth } \\
\text { rate }(\%)\end{array}$ & 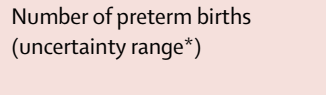 & $\begin{array}{l}\text { Number of } \\
\text { livebirths }\end{array}$ & $\begin{array}{l}\text { Preterm birth } \\
\text { rate }(\%)\end{array}$ & $\begin{array}{l}\text { Number of preterm births } \\
\text { (uncertainty range* })\end{array}$ & $\begin{array}{l}\text { Increase in } \\
\text { preterm } \\
\text { rate }(\%)\end{array}$ & $\begin{array}{l}\text { Average annual \% } \\
\text { increase in } \\
\text { preterm birth rate }\end{array}$ \\
\hline Developed regions & 15100000 & $7 \cdot 2 \%$ & $1090000(1035000-1179000)$ & 14300000 & $8.6 \%$ & $1233000(1189000-1345000)$ & $19 \cdot 4 \%$ & $1 \cdot 1 \%$ \\
\hline Latin America & 10900000 & $7 \cdot 7 \%$ & 845000 (707 000-1217 000) & 10200000 & $8 \cdot 4 \%$ & $853000(696000-1164000)$ & $9 \cdot 1 \%$ & $0.5 \%$ \\
\hline Caribbean & 769000 & $8.9 \%$ & $68000(48000-125000)$ & 683000 & $11 \cdot 2 \%$ & $77000(53000-142000)$ & $25 \cdot 8 \%$ & $1.5 \%$ \\
\hline Total & 26769000 & $7 \cdot 5 \%$ & 2004000 (1839000-2468 000) & 25183000 & $8.6 \%$ & $2163000(1987000-2593000)$ & $14 \cdot 7 \%$ & $0.8 \%$ \\
\hline
\end{tabular}

Estonia, had reductions in estimated preterm birth rates from 1990 to 2010. 14 countries had stable preterm birth rates $(<0 \cdot 5 \%$ annual change in preterm birth rates). In all other countries, the preterm birth rate was estimated to be greater in 2010 than in 1990. Comparison of the estimated trends with reported trends by country suggested that the model predicted trends close to reported data (appendix pp 76-81 for individual country rates).

\section{Discussion}

We estimated national preterm birth rates for 184 countries in the year 2010 suggesting a worldwide total of 14.9 million preterm births (uncertainty range $12 \cdot 3-18 \cdot 1$ million), more than one in ten of all babies (panel). Most preterm births (84\%, $12 \cdot 5$ million) occur after 32 completed weeks of gestation. Most of these newborns would survive with supportive care, and without neonatal intensive care. ${ }^{28}$ Yet, a huge survival and equity gap remains between the richest and poorest countries. ${ }^{28}$ Currently, more than $90 \%$ of babies born before 28 weeks of gestation survive in highincome countries, but in low-income settings, only $10 \%$ of these babies or less survive, a 90:10 survival gap. At the start of the 20th century, the UK and USA had neonatal mortality rates of 40 per 1000 livebirths - similar to Africa in 2000-but these were reduced to 15 per 1000 livebirths before neonatal intensive care was widely available. Over the decade 2000-2010, seven low-income and middleincome countries have halved their numbers of deaths due to preterm birth. ${ }^{29}$ Rapid reductions in deaths among preterm babies are possible and given the increasing proportion of deaths that are neonatal in children younger than 5 years, this could alter the trajectory of many countries towards MDG 4 for child survival. ${ }^{30}$ Strategies for maternal mortality reduction to meet the MDG 5 , such as family planning and obstetric care, can also improve pregnancy outcomes including preterm birth. ${ }^{31}$

We have highlighted the differences in preterm birth rates between countries, but substantial disparities exist within countries. For example, in the USA, reported preterm birth rates were as high as $17.5 \%$ in black Americans in 2009, compared with $10.9 \%$ in white Americans, with rates varying from about $11-12 \%$ in those $20-35$ years of age, to more than $15 \%$ in those younger than 17 years or older than 40 years. ${ }^{32}$
Preterm birth is more common in boys than girls, with about $55 \%$ of all preterm births being boys, ${ }^{33}$ and is associated with a higher risk of fetal and neonatal mortality $^{34-37}$ and of long-term impairments ${ }^{37,38}$ in boys than in girls born at a similar gestation. For both boys and girls, preterm birth has a major effect on child development and adult economic productivity. Recent studies show that even babies born at 34-37 weeks have an increased risk of immediate complications, ${ }^{39-41}$ neonatal and infant death, cerebral palsy, and worse neurodevelopmental and school performance outcomes when compared with those born at term..$^{42,43}$

Rates of preterm birth increased or were stable in all but three of the 65 countries with consistent data. This rise is partly due to increases in registration of extremely preterm births, which reflect improved case ascertainment rather than a genuine change in rate. ${ }^{44} \mathrm{An}$ increase in the proportion of preterm births occurring at $32-<37$ weeks, linked to increased provider-initiated preterm births secondary to changes in obstetric practices, has been reported over the past decades in some countries. ${ }^{45}$ However, for countries with available data in this study, we found no evidence of a change in the proportion of all preterm births that were $32-<37$ weeks from 1990 to $2010(\mathrm{p}=0 \cdot 9)$.

Low birthweight is a strong predictor in both statistical models. Although birthweight is closely linked with gestational age, it cannot be used interchangeably since there is a range of "normal" birthweight for a given gestational age and sex. In some settings, especially in South Asia, a high proportion of low birthweight babies are term babies who are small for gestational age. ${ }^{46}$ Distinguishing between the two is important as a baby born preterm has a higher risk of death than a baby of the same birthweight born small for gestational age at term. Babies who are both preterm and small for gestational age are at even higher risk than babies with one of the conditions. ${ }^{47}$

Maternal BMI is an important risk factor for preterm birth, and is of public health importance in its own right. BMI was retained as a predictor in the Model I; in developed and Latin American and the Caribbean regions where increasing mean female BMI was associated with increasing preterm birth rates. Whereas some studies 
have shown an increase in preterm birth with low BMI $\left(<18.5 \mathrm{~kg} / \mathrm{m}^{2}\right),{ }^{48-51}$ others support an increase in providerinitiated preterm birth with increasing BMI. ${ }^{49,52,53}$ The effect of high BMI is greater in primigravidae, and might be mediated by an increase in pre-eclampsia in this subgroup and potentially mediated by provider-initiated preterm births. ${ }^{49}$ A recent systematic review ${ }^{53}$ showed both increased induced preterm birth and overall preterm birth rates in overweight and obese women after accounting for publication bias.

Predictors of preterm birth retained in model II covering regions other than Developed or Latin America and the Caribbean included malaria and female literacy. Malaria is associated with an increased risk of preterm birth, especially in areas of unstable transmission. ${ }^{10,54,55}$ Somewhat counter-intuitively, female literacy is associated with increasing preterm birth rates. It may be that increased literacy is a marker of a "Western" lifestyle which Chinese immigrant cohort studies suggests may confer an increased risk of preterm birth. ${ }^{56}$

For 85 of the 184 countries included (17\% of livebirths worldwide), no data were available, whereas for a further 40 countries ( $54 \%$ of livebirths worldwide), the available data are unlikely to be nationally representative (appendix p 53). This limitation is shown by the wide uncertainty ranges, especially for countries with no nationally representative data. This data gap is most marked for the 48 countries in the sub-Saharan African region-where no available data exist for 28 countries, and the available data from the other 20 countries are unlikely to be nationally representative. A paucity of high quality data on the distribution of the subgroups of preterm birth was available from some regions, notably south Asia and subSaharan Africa. The quality of data on preterm birth depends on the extent to which births are correctly classified as preterm or not. This is highly dependent upon both the method of gestational age assessment used and the skill of the user. The method used can affect substantially the number of preterm births reported. For example, results from a large study $^{57}$ from a Canadian teaching hospital showed a preterm birth rate of $9.1 \%$ when assessed with ultrasound alone, compared with $7.8 \%$ in the same cohort when using LMP and ultrasound. LMP alone, although more feasible to record, is relatively imprecise (uncertainty range of about 3 weeks) because of variation in the length of menstrual cycle between women, conception occurring up to several days after ovulation and recall of the date of LMP being subject to errors. ${ }^{58}$

Data quality is particularly affected by under-registration of extremely preterm births, or their misclassification to stillbirths near the thresholds of perceived viability and stillbirth registration..$^{59}$ Countries using preterm birth definitions that include births from 20 weeks onwards report a higher proportion of preterm births under 28 weeks, possibly reflecting increased data capture of livebirths around the margins of viability (figure 5). Other countries with no specified lower cutoff have variable capture of
Panel: Research in context

\section{Systematic review}

Preterm birth is the largest cause of neonatal death worldwide and second leading cause of child deaths-1.1 million deaths a year. Yet, data on preterm birth rates is not routinely collected in many countries. We did a systematic search of online databases, National Statistical Offices, and Ministry of Health sources, and assessed reports according to pre-specified inclusion criteria. Search terms used included multiple variants of terms covering the following areas "preterm or premature" and "birth or labour" or "newborn or infant", and Medical Subject Headings terms when available. Additional data were collected through a WHO country consultation process. A total of 738 datapoints from 99 countries met inclusion criteria and were used to model estimates of preterm birth rates for 184 countries, with time trends for 65 countries in regions with reliable data

\section{Interpretation}

These are the first national estimates of preterm birth rates suggesting that in 2010, 11.1\% of all livebirths worldwide were born preterm, ranging from around $5 \%$ in several northern European countries to $18.1 \%$ (Malawi), and that the rates of preterm birth are increasing in those regions with reliable data. Over $60 \%$ of the 14.9 million babies born preterm in 2010 were born in south Asia and sub-Saharan Africa. However preterm birth affects rich and poor countries, with Brazil and USA featuring in the 10 countries with the highest numbers of preterm births. Boys are at higher risk of preterm birth and of adverse outcomes than girls. The high and rising incidence of preterm birth, associated with death and disability, represents a significant public health impact in all countries. Preventive approaches have had poor national impact so far, and innovative solutions are urgently needed. However, major progress has been made in mortality for preterm babies in high income countries. Rapid scale up of basic interventions in low-income and middle-income countries could accelerate progress towards Millennium Development Goal 4 for child survival in 2015 and beyond.

extremely preterm babies. When reporting thresholds are changed it might take some time before recording of cases near the new threshold improves. For example, Denmark changed their lower threshold for registering preterm births from 28 to 22 weeks in 1997, but it was several years later that the proportion of all preterm births under 28 weeks increased from $4 \%$ to $7 \%$ (figure 6 ). We excluded 20 datapoints from our input dataset based on the implausibility criteria of less than $2 \%$ of preterm births being at less than 28 weeks' gestation (figure 2). We did a sensitivity analysis regarding these exclusions and found no evidence of a systematic difference between the estimated preterm birth rates at country level with and without these data included (paired $t$ test $\mathrm{p}=0 \cdot 44$ ).

We applied statistical modelling to try to correct for definition variation, data limitations, and to estimate for countries for which no or poor data were available. The use of statistical models can never be a substitute for improved empirical data. Prediction of the prevalence of preterm birth, in essence a syndrome and with varying risk factors around the world, has presented modelling challenges. The predictor variables available as time series are poor when compared with the complex interplay of different factors leading to preterm birth. Particularly, it was not possible to distinguish between spontaneous and provider-initiated preterm births, since even in highincome countries, this distinction is not readily available 


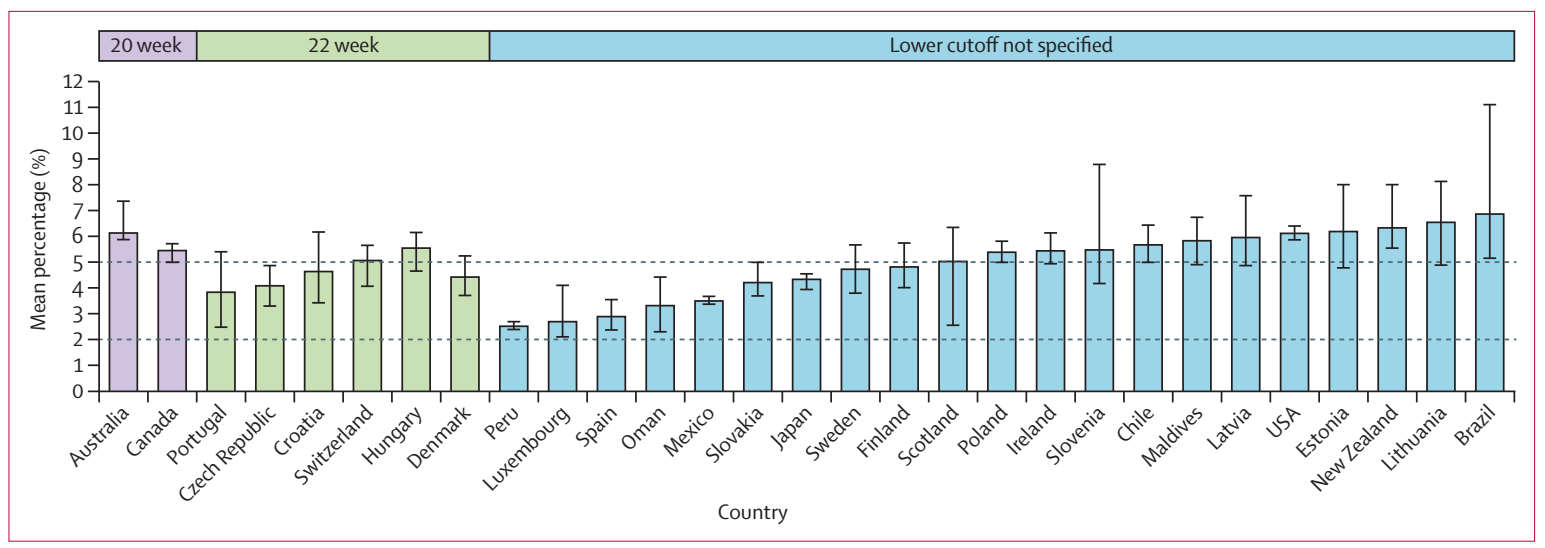

Figure 5: Percentage of reported preterm births that are less than 28 weeks by country showing variation with different lower gestational age thresholds Data from 29 countries with more than one reported datapoint providing information on the proportion of preterm births that are $<28$ weeks from 1990 to 2010 . Error bars show range of reported proportions. All these countries report using livebirths as numerator or denominator. The $5 \%$ standard is based on meta-analysis shown in table 1. For estimation input dataset $<2 \%$ was considered implausible and the data were excluded.

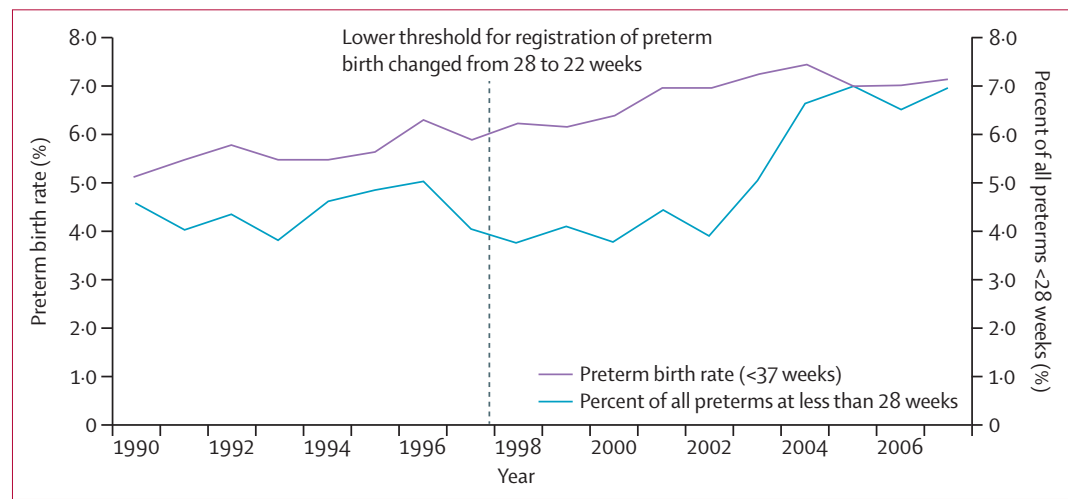

Figure 6: Variation in preterm birth rate and proportion of preterm births at less than 28 weeks with a reduction in the lower threshold for registration of preterm births from 28 to 22 weeks' gestation in Denmark Analysis of 1191000 livebirths 1990 to 2007 Data source: National Board of Health. ${ }^{60}$

at national level or consistently over time. Tracking "medically-indicated" versus "non-indicated" providerinitiated preterm births would be crucial for accountability in reduction of unnecessary caesareans, but definitions and data are missing.

Improved quality and quantity of preterm birth data are needed in every country, but especially in low-income countries. Efforts in every country should be directed to the increase of coverage and systematic recording of all births, whether live or stillborn in a standard reporting format, which includes both birthweight and estimated gestational age. Application of a standard definition for preterm birth in terms of both the numerator and the denominator is essential. We have used the standard ICD 10 definition focusing on all livebirths at less than 37 weeks' gestation. A 28 week threshold was mentioned in ICD 10 , but since the last edition, increased viability at lower gestational ages calls for this threshold to be reviewed, and consequently, very few countries are now applying this as a threshold for reporting (figure 5). ${ }^{18} \mathrm{We}$ recommend the use of an additional data quality marker regarding the percent of liveborn preterm babies under
$1000 \mathrm{~g}$ or 28 weeks of gestation because of highly variable reporting of this group of babies and variable practices in resuscitation of the "micro preemie" group under 26 weeks' gestation. ${ }^{61}$ The ICD 11 process provides an opportunity to give clear guidelines regarding this and other perinatal birth and death certificate issues, relevant to both high-income and low-income contexts.

Our estimates indicate a large burden among liveborn babies. Although focusing on livebirths is important to monitor neonatal and longer term outcomes, data on stillbirths are required to measure the full burden and to assist in the interpretation of trends in the preterm birth rate in liveborns, given potential misclassification between stillbith and livebirth in preterm babies and changing trends which might relate to obstetric care. In developed countries, between $5 \%$ and $10 \%$ of all preterm births are stillbirths, most of which constitute antepartum preterm stillbirths. ${ }^{62}$ Advanced fetal medicine and obstetric and neonatal intensive care are routinely available, so babies not growing well in utero can be delivered early, reducing stillbirths, especially late stillbirths, but increasing preterm birth rates. In some countries, including the USA, this trend is reported to be at least partly responsible for the overall increase in the preterm birth rate from 1990 to 2007 and the decline in perinatal mortality. ${ }^{63}$ This number contrasts with the large burden of 1.2 estimated million intrapartum stillbirths in lowincome settings, which are mostly term babies and could be prevented with obstetric care. ${ }^{17}$

One option for increasing the amount of populationbased data available in high-burden countries is to develop and test survey-based modules for consideration in nationally representative surveys such as the Demographic and Health Surveys (DHS) and demographic surveillance sites. These surveys are the major source of data for mortality and coverage tracking in most low-income countries. Innovation of locally appropriate, simpler, low-cost, methods for assessing birthweight and gestational age could improve both the coverage and quality of gestational 
age assessment, for example, based on simplified clinical assessment for example of foot size. ${ }^{64}$ Data from hospitalbased information systems would also be helpful, but potential selection and other biases must be taken into account. Additionally, achieving consensus around comparable case definitions and improving the recording of the different categories of preterm birth (eg, spontaneous vs provider-initiated), although challenging, is needed to monitor changes with increased caesarean sections.? Improved standardised methods to assess acute and longterm morbidities associated with preterm birth are essential to track the proportion of impaired survivors.

Strengthened data systems are needed to record all pregnancy outcomes including maternal, stillbirth, preterm birth, low birthweight, and neonatal mortality. Consistent with ICD, we recommend adding a data quality indicator of the percent of all live preterm births that are under 28 weeks. Preterm birth is a syndrome and distinguishing important subgroupings is important to inform programmatic interventions.

Preterm birth prevention currently has few high impact solutions. Recent investments in discovery research show increasing recognition of this important knowledge gap. ${ }^{65}$ However, new preterm prevention solutions will take years to develop and deliver. In the meantime, urgent action is required to increase survival and reduce disability in those born preterm, especially in the lowest income settings in which even moderate and late preterm babies die needlessly. Parent groups in high-income countries have been a powerful mobilising force yet, in low-income settings, these preventable deaths are accepted as inevitable by parents and often by health-care workers. About $84 \%$ of all preterm babies are moderate and late preterm, most of whom should survive with supportive care and feasible interventions such as antenatal steroids ${ }^{66}$ and kangaroo mother care, ${ }^{67}$ which would accelerate progress towards MDG 4 for child survival. ${ }^{28}$ Preterm birth will be increasingly important beyond 2015 as an unfinished agenda for child survival and an important approach to improve health and sustainable development. Many countries cannot afford to rapidly scale up neonatal intensive care. Yet, no country can afford to miss simple care for every baby and investing extra attention in survival and health of newborns that are born too soon.

\section{Contributors}

$\mathrm{HB}$ coordinated the literature searches, undertook the modelling with SC, JL, and MO and drafted the report with JL, SC, and MO. DC, ABM, and LS undertook the identification and data abstraction of the national registry data. RN, AA, and GVG undertook the literature searches and abstraction. SR compiled the covariate time series. JL and LS initiated the process. JL oversaw the process and drafted the manuscript with HB. All authors reviewed the manuscript.

\section{Conflicts of interest}

We declare that we have no conflicts of interest.

\section{Acknowledgments}

This analysis was funded by the Bill \& Melinda Gates Foundation through grants to US Fund for UNICEF for the Child Health Epidemiology Reference Group and to Save the Children's Saving Newborn Lives programme, with additional funding from March of Dimes, the World
Health Organization, Department of Reproductive Health and Research, and the Partnership for Maternal Newborn and Child Health. We thank Mary Kinney and Erica Corbett for help with covariate time series data, and Florence Rusciano for generating the maps. We thank Colin Mathers and Mie Inoue for reviewing data and supporting the county consultation process, and Alexandre Peregoudov for their assistance with translation. We thank Joanne Katz and Anne CC Lee, Louise Day, and LAMB MISResearch Department, Aroonsri Mongkolchati, Jean Humphrey, Gordon Smith, Nanbert Zhong, and James Tielsch and colleagues who provided preterm birth rate data and reanalysed data according to the standard definition when necessary. We also thank WHO Member States, country and regional offices for their participation and collaboration during country consultation.

\section{References:}

1 Liu L, Johnson H, Cousens S, et al, for the Child Health Epidemiology Reference Group of WHO and UNICEF. Global, regional, and national causes of child mortality: an updated systematic analysis for 2010 with time trends since 2000. Lancet 2012; Published online May 11. DOI:10.1016/S0140-6736(12)60560-1.

2 Lawn JE, Kerber K, Enweronu-Laryea C, Cousens S. 3.6 million neonatal deaths-what is progressing and what is not? Semin Perinatol 2010; 34: 371-86.

3 Lawn JE, Cousens S, Zupan J, Lancet Neonatal Survival Steering T. 4 million neonatal deaths: when? Where? Why? Lancet 2005; 365: 891-900.

4 Mwaniki MK, Atieno M, Lawn JE, Newton CR. Long-term neurodevelopmental outcomes after intrauterine and neonatal insults: a systematic review. Lancet 2012; 379: 445-52.

5 Born too soon: global action report for preterm birth. New York: MoD, PMNCH, Save the Children, WHO; 2012.

6 WHO. WHO: recommended definitions, terminology and format for statistical tables related to the perinatal period and use of a new certificate for cause of perinatal deaths. Modifications recommended by FIGO as amended October 14, 1976. Acta Obstet Gynecol Scand 1977; 56: 247-53.

7 Goldenberg RL, Gravett MG, Iams J, et al. The preterm birth syndrome: issues to consider in creating a classification system. Am J Obstet Gynecol 2012; 206: 113-18.

8 Lawn JE, Kinney M, Lee AC, et al. Reducing intrapartum-related deaths and disability: can the health system deliver? Int J Gynaecol Obstet 2009; 107 (suppl 1): S123-40, S40-42.

9 Gyamfi-Bannerman C, Fuchs KM, Young OM, Hoffman MK. Nonspontaneous late preterm birth: etiology and outcomes. Am J Obstet Gynecol 2011; 205: 456 e1-6.

10 Steer P. The epidemiology of preterm labour. BJOG 2005; 112 (suppl 1): 1-3.

11 Menon R. Spontaneous preterm birth, a clinical dilemma: etiologic, pathophysiologic and genetic heterogeneities and racial disparity. Acta Obstet Gynecol Scand 2008; 87: 590-600.

12 Plunkett J, Muglia LJ. Genetic contributions to preterm birth: implications from epidemiological and genetic association studies. Ann Med 2008; 40: 167-95.

13 Goldenberg RL, Culhane JF, Iams JD, Romero R. Epidemiology and causes of preterm birth. Lancet 2008; 371: 75-84.

14 Muglia LJ, Katz M. The enigma of spontaneous preterm birth. $N$ Engl J Med 2010; 362: 529-35.

15 Petrou S, Henderson J, Bracewell M, Hockley C, Wolke D, Marlow N. Pushing the boundaries of viability: the economic impact of extreme preterm birth. Early Hum Dev 2006; 82: 77-84.

16 WHO. ICD-10: international statistical classificiation of diseases and related health problems: tenth revision. 2nd edn. $2004 \mathrm{http}: / /$ www.who.int/classifications/icd/ICD-10_2nd_ed_volume2.pdf (accessed Oct 9, 2011).

17 Lawn JE, Blencowe H, Pattinson R, et al. Stillbirths: Where? When? Why? How to make the data count? Lancet 2011; 377: 1448-63.

18 Joseph KS, Liu S, Rouleau J, et al. Influence of definition based versus pragmatic birth registration on international comparisons of perinatal and infant mortality: population based retrospective study. BMJ 2012; 344: e746.

19 Beck S, Wojdyla D, Say L, et al. The worldwide incidence of preterm birth: a systematic review of maternal mortality and morbidity. Bull World Health Organ 2010; 88: 31-38. 
20 Boerma JT, Mathers C, Abou-Zahr C. WHO and global health monitoring: the way forward. PLoS Med 2010; 7: e1000373.

21 Millennium Development Indicators: World and regional groupings. http://mdgs.un.org/unsd/mdg/Host. aspx?Content=Data/RegionalGroupings (accessed Jan 3, 2012).

22 Centers for Disease Control and Prevention. Reproductive health surveys. http://1.usa.gov/Kpokoa (accessed Oct 9, 2011).

23 Gülmezoglu AM, Say L, Betran AP, et al. WHO systematic review of maternal mortality and morbidity: methodological issues and challenges. BMC Med Res Methodol 2004; 4: 16.

24 UN Statistics Division. Information on national statistical systems. http://unstats.un.org/unsd/methods/inter-natlinks/sd_natstat.asp (accessed Sept 23, 2011).

25 WHO, UNICEF, UNFPA, and The World Bank. Trends in maternal mortality: 1990 to 2008. 2010. http://whqlibdoc.who.int/publications/ 2010/9789241500265_eng.pdf (accessed March 27, 2012).

26 Cousens S, Blencowe H, Stanton C, et al. National, regional, and worldwide estimates of stillbirth rates in 2009 with trends since 1995: a systematic analysis. Lancet 2011; 377: 1319-30.

27 UN Population Division. World population prospects. 2010. http:// esa.un.org/unpd/wpp/index.htm (accessed Oct 9, 2011).

28 Lawn J, Davidge R, Paul V, et al. Chapter 5: Preterm baby survival and care around the world. In: Howson CP, Kinney MV, Lawn JE, eds. Born too soon: the global action report on preterm birth. New York: March of Dimes, PMNCH, Save the Children, WHO, 2012: 60-77.

29 Preterm Birth Action Group. Chapter 6: Action and the way forward. In: Howson CP, Kinney MV, Lawn JE, eds. Born too soon: the global action report on preterm birth. New York: March of Dimes, PMNCH, Save the Children, WHO, 2012: 78-101.

30 UN. Child health millennium development indicators. http://www. un.org/millenniumgoals/childhealth.shtml (accessed Feb 18, 2012).

31 UN. Maternal health millennium development indicators. http://www. un.org/millenniumgoals/maternal.shtml (accessed Feb 18, 2012).

32 Martin JA, Hamilton BE, Ventura SJ, et al. Births: final data for 2009. National vital statistics reports; vol 60 no 1. Hyattsville, MD: National Center for Health Statistics, 2011.

33 Zeitlin J, Saurel-Cubizolles MJ, De Mouzon J, et al. Fetal sex and preterm birth: are males at greater risk? Hum Reprod 2002; 17: 2762-68.

34 Stevenson DK, Verter J, Fanaroff AA, et al. Sex differences in outcomes of very low birthweight infants: the newborn male disadvantage. Arch Dis Child Fetal Neonatal Ed 2000; 83: F182-85.

35 Smith GC. Sex, birth weight, and the risk of stillbirth in Scotland, 1980-1996. Am J Epidemiol 2000; 151: 614-19.

36 Khoury MJ, Marks JS, McCarthy BJ, Zaro SM. Factors affecting the sex differential in neonatal mortality: the role of respiratory distress syndrome. Am J Obstet Gynecol 1985; 151: 777-82.

37 Kent AL, Wright IM, Abdel-Latif ME. Mortality and adverse neurologic outcomes are greater in preterm male infants. Pediatrics 2012; 129: 124-31.

38 Verloove-Vanhorick SP, Veen S, Ens-Dokkum MH, Schreuder AM, Brand R, Ruys JH. Sex difference in disability and handicap at five years of age in children born at very short gestation. Pediatrics 1994; 93: 576-79.

39 Escobar GJ, Clark RH, Greene JD. Short-term outcomes of infants born at 35 and 36 weeks' gestation: we need to ask more questions. Semin Perinatol 2006; 30: 28-33.

40 Teune MJ, Bakhuizen S, Gyamfi Bannerman C, et al. A systematic review of severe morbidity in infants born late preterm. Am J Obstet Gynecol 2011; 205: 374 e1-9.

41 Femitha P, Bhat BV. Early neonatal outcome in late preterms. Indian J Pediatr 2011; published online Dec 9, 2011. DOI:10.1007/ s12098-011-0620-9.

42 Woythaler MA, McCormick MC, Smith VC. Late preterm infants have worse 24-month neurodevelopmental outcomes than term infants. Pediatrics 2011; 127: e622-29.

43 Quigley MA, Poulsen G, Boyle E, et al. Early term and late preterm birth are associated with poorer school performance at age 5 years: a cohort study. Arch Dis Child Fetal Neonatal Ed 2012; 97: F167-73.

44 Consultative Council on Obstetric and Paediatric Mortality and Morbidity. Annual Reports for the years 1991 and 1999. Melbourne: Consultative Council on Obstetrics and Paediatric Mortality and Morbidity, 1992 and 2001.
45 Davidoff MJ, Dias T, Damus K, et al. Changes in the gestational age distribution among U.S. singleton births: impact on rates of late preterm birth, 1992 to 2002. Semin Perinatol 2006; 30: 8-15.

46 Barros FC, Barros AJ, Villar J, Matijasevich A, Domingues MR, Victora CG. How many low birthweight babies in low- and middle-income countries are preterm? Rev Saude Publica 2011; 45: 607-16.

47 Qiu X, Lodha A, Shah PS, et al. Neonatal outcomes of small for gestational age preterm infants in Canada. Am J Perinatol 2011; 29: 87-94.

48 Hendler I, Goldenberg RL, Mercer BM, et al. The preterm prediction study: association between maternal body mass index and spontaneous and indicated preterm birth. Am J Obstet Gynecol 2005; 192: 882-86.

49 Smith GC, Shah I, Pell JP, Crossley JA, Dobbie R. Maternal obesity in early pregnancy and risk of spontaneous and elective preterm deliveries: a retrospective cohort study. Am J Public Health 2007; 97: 157-62.

50 Schieve LA, Cogswell ME, Scanlon KS, et al. Prepregnancy body mass index and pregnancy weight gain: associations with preterm delivery. The NMIHS Collaborative Study Group. Obstet Gynecol 2000; 96: 194-200.

51 Kramer MS, Coates AL, Michoud MC, Dagenais S, Hamilton EF, Papageorgiou A. Maternal anthropometry and idiopathic preterm labor. Obstet Gynecol 1995; 86: 744-48.

52 Torloni MR, Betran AP, Daher S, et al. Maternal BMI and preterm birth: a systematic review of the literature with meta-analysis. J Matern Fetal Neonatal Med 2009; 22: 957-70.

53 McDonald SD, Han Z, Mulla S, Beyene J. Overweight and obesity in mothers and risk of preterm birth and low birth weight infants: systematic review and meta-analyses. BMJ 2010; 341: c3428

54 Shulman CE, Dorman EK. Importance and prevention of malaria in pregnancy. Trans $R$ Soc Trop Med Hyg 2003; 97: 30-35.

55 Desai M, ter Kuile FO, Nosten F, et al. Epidemiology and burden of malaria in pregnancy. Lancet Infect Dis 2007; 7: 93-104

56 Newnham JP, Sahota DS, Zhang CY, et al. Preterm birth rates in Chinese women in China, Hong Kong and Australia-the price of Westernisation. Aust N Z J Obstet Grnaecol 2011; 51: 426-31.

57 Blondel B, Morin I, Platt RW, Kramer MS, Usher R, Breart G Algorithms for combining menstrual and ultrasound estimates of gestational age: consequences for rates of preterm and postterm birth. BJOG 2002; 109: 718-20.

58 Kramer MS, McLean FH, Boyd ME, Usher RH. The validity of gestational age estimation by menstrual dating in term, preterm, and postterm gestations. JAMA 1988; 260: 3306-08.

59 Froen JF, Gordijn SJ, Abdel-Aleem H, et al. Making stillbirths count, making numbers talk - issues in data collection for stillbirths. BMC Pregnancy Childbirth 2009; 9: 58.

60 National Board of Health. Copenhagen S, Denmark. http://www. sundhedsstyrelsen.dk/Udgivelser/Soegning.aspx?terms=F\%c3\%b8 dselsregisteret+\&pubonly=true (accessed Oct 9, 2011).

61 Nuffield Council on Bioethics. Critical care decisions in fetal and neonatal medicine: ethical issues. 2006. http://www. nuffieldbioethics.org/neonatal-medicine (accessed Feb 9, 2012).

62 Flenady V, Middleton P, Smith GC, et al. Stillbirths: the way forward in high-income countries. Lancet 2011; 377: 1703-17.

63 Ananth CV, Vintzileos AM. Epidemiology of preterm birth and its clinical subtypes. J Matern Fetal Neonatal Med 2006; 19: 773-82.

64 Marchant T, Jaribu J, Penfold S, Tanner M, Armstrong Schellenberg J. Measuring newborn foot length to identify small babies in need of extra care: a cross sectional hospital based study with community follow-up in Tanzania. BMC Public Health 2010; 10: 624.

65 Gravett MG, Rubens CE, Nunes TM. Global report on preterm birth and stillbirth (2 of 7): discovery science. BMC Pregnancy Childbirth 2010; 10 (suppl 1): S2.

66 Mwansa-Kambafwile J, Cousens S, Hansen T, Lawn JE. Antenatal steroids in preterm labour for the prevention of neonatal deaths due to complications of preterm birth. Int J Epidemiol 2010; 39 (suppl 1): i122-33.

67 Conde-Agudelo A, Belizan JM, Diaz-Rossello J. Kangaroo mother care to reduce morbidity and mortality in low birthweight infants. Cochrane Database Syst Rev 2011; 3: CD002771. 